\title{
Advantages of using raw materials in ancient and recent buildings
}

\author{
A. Murta \\ University of Trás-os-Montes e Alto Douro, Vila Real, Portugal
}

H. Varum

University of Aveiro, Aveiro, Portugal

\section{J. Pinto}

University of Trás-os-Montes e Alto Douro, Vila Real, Portugal

\begin{abstract}
Many of the existing buildings constructed mostly with natural raw materials, in European sites, are frequently lacking proper maintenance and, therefore, a high degree of degradation is verified in these buildings compromising their integrity and reducing their lifetime probability. Often in the rehabilitation or reconstruction of old buildings the solution adopted is the partial or integral demolition and substitution of several building components. The aims of this study are to describe the most common constructive solutions in Portuguese buildings constructed with raw natural materials, to specify the principal problems that affect each building component, and to present possible solutions to correct each defect. This study is focused on the principal elements that compose the building structures in Portugal, including load-bearing walls, wooden floor and roof structures. The architecture solution, the structure solution, the building material's identification/characterization, the sequence of structural failures and the main pathologies identification/characterization related to an early XX century Portuguese watermill were described and detailed. It may be considered as a real scale experimental model which may contribute to the rehabilitation and conservation fields of traditional Portuguese buildings. The structural failure sequence was analyzed, the corrective solutions presented and studied privileges the adoption of materials and techniques similar and most compatible with the original ones. It's also presented the structural solution savings of energy consumption and $\mathrm{CO}_{2}$ emission. The results of this study were found to be easily extrapolated to the repairing of the Portuguese traditional buildings which are in general environmental friendly.
\end{abstract}




\section{Introduction}

In Portugal, the main traditional construction techniques that make use of earth are rammed earth, adobe and half-timbered. These techniques fell into disuse upon the appearance of reinforced concrete and ceramic bricks [1].

An expressive amount of the existing Portuguese buildings are old buildings which frequently reveal a certain lack of maintenance or conservation and the main reason for this fact is inherent to cost reasons. The cause of these premature pathologies may be building error, design error, inappropriate building conception, inappropriate or deficient building materials, among others and may result in partial or total collapses of the constructions. The occurrence of pathology may lead to others and, in the limit, may results in a progressive structural collapse [2].

A regular maintenance or conservation work is required to avoid unexpected building deterioration [3].

Based on the concept of "inform to prevent", a research project was launched at the University of Trás-os-Montes e Alto Douro (UTAD) with the main purpose of transmitting to an expressive percentage of the population the urgency of having a sustainable attitude in all the activities and, in particular, in the construction field. Considering that, sustainable construction can be divided in four main areas which are: efficient energy use, sustainable urban planning, efficient water management and sustainable building construction.

In the context of sustainable building construction an early XX century Portuguese watermill building is used in this research work as a study case to show how a roof leaking may lead to a progressive building collapse.

A brief description of the building is done followed by an identification/characterization of the building materials. In particular, an experimental study of the structural mortar was done in the Microscopic Electronic Unit of (UTAD). The chronological partial roof structural failure sequence is presented and described, in which a pathology cause/effect relation is also done. Meanwhile, the analysis of this failure sequence may give evidence for achieving better robust timber structural roof solutions and also reinforcement repairing structures proposals for traditional Portuguese buildings that are also presented in this study.

\section{Sustainability}

The Earth planet must be seen as a delicate ecosystem which its equilibrium requires urgent attention. We consider that the main threats to sustainability are, by order of impact scale, the industry, human behavior and natural hazards (i.e. forest fire, volcanic eruption, among others). They may be interconnected to each other in certain ways. The sustainable system flowchart of Figure 2.1 is proposed. 


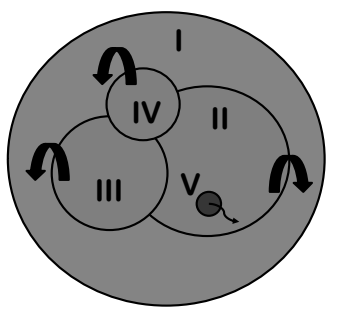

\section{I - Green Earth Planet}

II - Industry

III - Human Behavior

IV - Natural Hazard

V - Building Industry

Fig. 2.1. Sustainable system flowchart

According to Figure 2.1, industry is a big field system and the main cause of $\mathrm{CO}_{2}$ emission to atmosphere. The building industry is a set of that field system and it is the goal of this research work.

Each building material has associated a specific cost, an energy consumption and a quantity of noxious gases released into the atmosphere, which resulted from all the phases related to its life-cycle such as the extraction from the raw material, transportation, transformation, building process, maintenance, demolition and recycling.

Several research studies [4-6] have been focused on estimating the quantity of the above environmental parameters.

Table 2.1 shows some values of energy consumption for the building materials which are considered in this research work, [4-6]. Comparing these values it is noticed that there is an expressive difference among them. According to [6], this fact may be related to the different approaches used by each author concerning different period of time for the material life-cycle and/or different fabrication techniques.

Table 2.1. Energy consumption $(\mathrm{MJ} / \mathrm{kg})$.

\begin{tabular}{lllll}
\hline \hline Material & $\begin{array}{l}\text { KangHee } \\
{[4]}\end{array}$ & $\begin{array}{l}\text { Leiden } \\
{[5]}\end{array}$ & $\begin{array}{l}\text { Baird } \\
{[6]}\end{array}$ & $\begin{array}{l}\text { Alcorn } \\
{[6]}\end{array}$ \\
\hline Concrete & 0.52 & 0.48 & 1.99 & 1.95 \\
Bar steel & 38.66 & ---- & 59.00 & 8.90 \\
Mortar & 0.40 & 0.88 & 2.49 & 1.33 \\
Brick & 2.95 & 0.15 & 2.50 & ---- \\
Earth adobe & 0.06 & ----- & 0.42 & ---- \\
Gravel & 0.15 & ---- & 0.30 & 0.10 \\
Pine wood & 4.44 & ---- & 8.08 & 0.10 \\
Sand & 0.05 & ---- & 0.04 & 7.80 \\
Cement & 3.33 & ----- & 8.98 & ---- \\
Earth & 0.05 & ---- & ---- & \\
\hline
\end{tabular}




\section{Description of the study case}

In this research work, the building adopted as a study case is an early XX century Portuguese watermill (Fig. 3.2 and 3.3).

The building is located in Portugal continental central region, on the coast, in the district of Coimbra, in the Municipality of Figueira da Foz, in the village of Carritos.

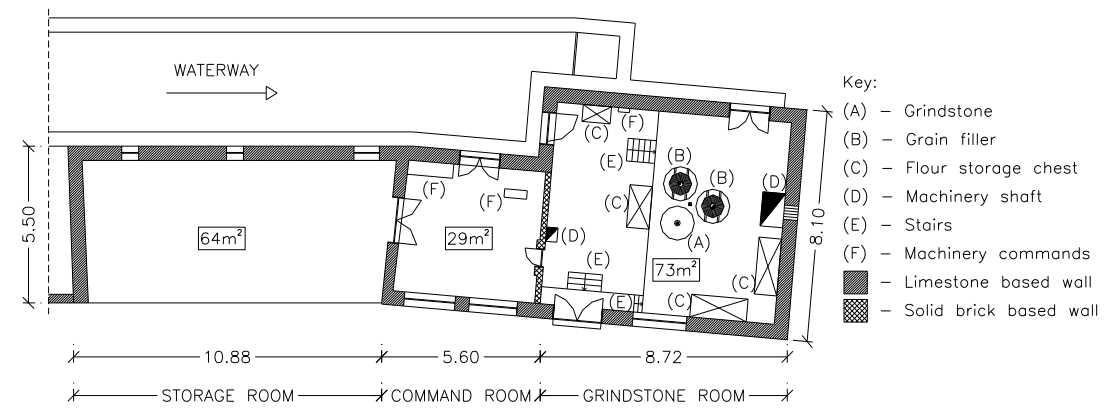

Fig. 3.2. Ground floor Plant, 2009 (m)

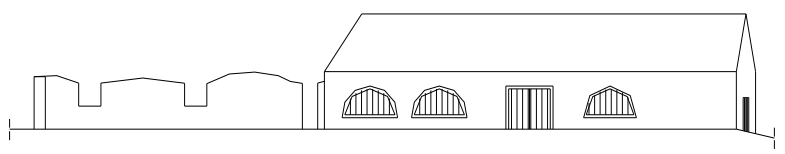

Fig. 3.3. Frontal view, 2009

\section{Identification and characterization of the building materials}

The used building materials are limestone, structural mortar, timber, solid and hollow ceramic bricks, finishing plaster and ceramic tiles.

Since this region is sparse in stones, the structural stone masonries walls (exterior and interior) had been built up using irregular and small sized limestone pieces (Fig. 4.1, detail I) agglutinated by a structural mortar (Fig. 4.1, detail II). The average thickness of these walls is $0.40 \mathrm{~m}$.

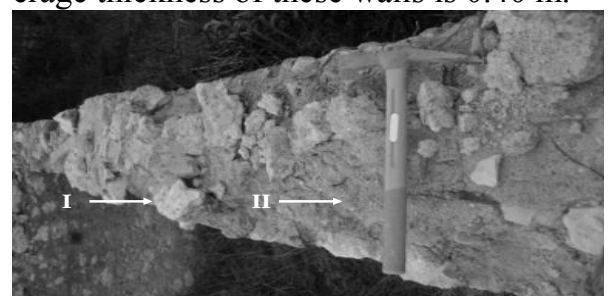

Fig. 4.1. Detail of the structural stone masonries walls 
Timber was highly used in this building. The floor, the purling, the beams of the roof structure and over the openings (windows and doors) and the ground pavement are timber. A finishing plaster material was used in most of the walls excluding the ones of the storage room. The exterior covering of the roof is ceramic tiles.

In order to identify the type of mortar, the type of finishing plaster and the specimen of timber, experimental tests were done.

The identification/characterization of the chemical and mineralogical elementary compositions of the mortar and the finishing plaster materials was done by scanning electron microscopy/energy dispersive spectroscopy (SEM/EDS) and Xray tests which were performed in the Microscopic Electronic Unity of UTAD. Similar tests have been already done in the framework of other research projects [7-8] to characterize the available and used materials for the local traditional constructions.

Four mortar material samples (Sample 1, 2, 3 and 4) were collected and tested. It was also tested a lime sample and a hydraulic lime sample since they are the most common binding material used in these traditional buildings.

The chemical elementary composition results obtained by the SEM/EDS test are presented in Table 4.1. The mineralogical elementary composition results of the X-ray test shown in Table 4.2.

Table 4.1. Chemical elementary composition results of the SEM/EDS (\%).

\begin{tabular}{lcccccc}
\hline \hline $\begin{array}{l}\text { Chemical } \\
\text { Element }\end{array}$ & Sample 1 & Sample 2 & Sample 3 & Sample 4 & Lime & $\begin{array}{l}\text { Hydraulic } \\
\text { lime }\end{array}$ \\
\hline \hline Oxygen (O) & 52.01 & 51.44 & 52.07 & 49.06 & 56.06 & 39.85 \\
Sodium (Na) & ----- & ---- & ----- & 0.90 & ---- & ----- \\
Magnesium (Mg) & ---- & ---- & ---- & 0.68 & 2.01 & 0.50 \\
Aluminium (Al) & 6.37 & 6.11 & 8.74 & 6.68 & 3.40 & 0.38 \\
Silicon (Si) & 13.84 & 9.45 & 17.48 & 15.01 & 7.42 & ----- \\
Chorine (Cl) & ----- & ----- & ---- & 0.58 & ---- & ---- \\
Potassium (K) & 1.90 & 1.09 & 3.45 & 1.65 & 0.99 & ---- \\
Calcium (Ca) & 24.92 & 31.17 & 17.36 & 22.51 & 28.01 & 59.26 \\
Iron (Fe) & 0.96 & 0.74 & 0.90 & 2.94 & 1.40 & ----- \\
\hline
\end{tabular}

Table 4.2. Mineralogical elementary composition results of the X-ray test

\begin{tabular}{ll}
\hline \hline Sample 1 & Mineralogical composition \\
\hline \hline Sample 1 & Quartz, Calcite, Muscovite \\
Sample 2 & Calcite, Kaolinite, Quartz \\
Sample 3 & Calcite, Quartz \\
Sample 4 & Calcite, Quartz, Plaster \\
Lime & Calcite,Calcium Oxide \\
Hydraulic lime & Calcite, Quartz, Plaster \\
\hline \hline
\end{tabular}


Mortar material samples 1, 2 and 3 have similar elementary composition in particular in terms of chemical (Table 4.1). Based on these results and the above analyses we may consider that the mortar material samples 1,2 and 3 are a mixture of local earth and lime and the mortar material sample 4 is a mixture of a local earth and hydraulic lime.

Two timber samples of the timber structural roof were experimentally identified as being Pinus pinea specimens. One timber sample of the ground floor pavement was experimentally identified as being Pinus pinaster specimen. These are both local trees specimens.

Based on the above building material description it is possible to realize that most of the used materials are natural and local and, the building itself is associated to building techniques that require small amount of energy consumption and releases an unexpressive amount of noxious gases to atmosphere [9]. Consequently, we have a remarkable example of a sustainable building solution.

According to [9], a sustainable structure like the one of this study will reveal a reduction of the energy consumption and noxious gases emissions amounts of over $60 \%$ when compared to a traditional column/beam concrete structure.

\section{Structural solution}

According to Fig. 3.2 there are two types of walls. There are several limestone based masonries walls and one solid ceramic brick based wall.

The roof timber structural solution comprises two types. In the grind stone and the command rooms (Fig. 5.1-a) it was adopted trusses (Fig. 5.1-a, detail I) directly supported on the limestone based masonries walls (Fig. 5.1-a, detail II), these trusses support beams (Fig. 5.1-a, detail III) which are supporting the purling (Fig. 5.1-a, detail IV). On the purling there are timber boards (Fig. 5.1-a, detail V) supporting the ceramic tiles.

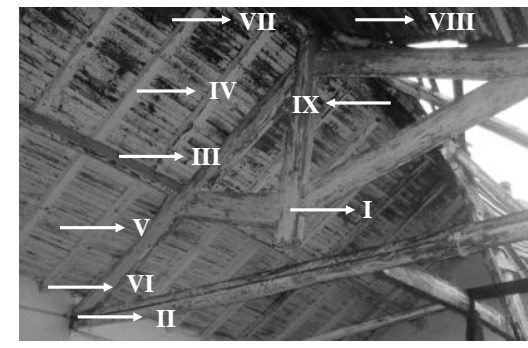

a. Trussed type roof structural solution

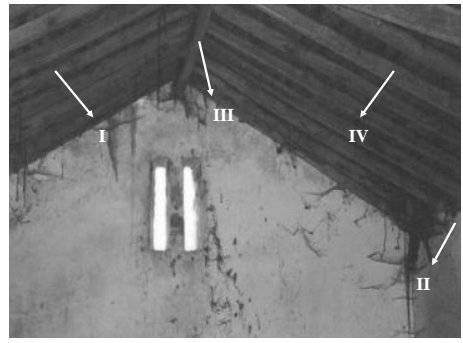

b. Beamed type roof structural solution

Fig. 5.1. Roof structural systems

The other type of roof timber structural solution was only applied in the storage room, Fig. 5.1-b, which includes timber beams (Fig 5.1-b. detail I) which were 
structures supported on the limestone based masonry walls (Fig. 5.1-b, detail II) and a central timber beam (Fig. 5.1-b, detail III). On these timber beams there were timber boards (Fig. 5.1-b, detail IV) supporting the ceramic tiles.

These are remarkable traditional timber structures built under skills based on experience.

\section{Failures and pathologies}

\subsection{Roof structural failures sequence}

The roof timber structure has been facing partial collapses throughout the last nine years. The first partial collapse occurred in 2000, in which part of the roof of the storage room was lost (Fig. 6.1-a, detail I). It is important to underline that the main structural timber elements which are trusses did not get damaged.

The second structural failure of the roof occurred in 2007 resulting in the completely loss of the roof of the storage room (Fig. 6.1-b, detail I) and part of the frontal limestone based masonry wall (Fig. 6.1-b, detail II).

In 2009 , the third roof structural failure occurred and the roof of the grindstone room suffered a partial collapse (Fig. 6.1-c, detail I) In this case, the purling (Fig 6.1-a, detail IV) collapsed in the zone of their support (the limestone based masonry wall (Fig. 6.1-a, detail VI) generating a load redistribution which resulted on the collapse of the beam (Fig. 6.1-a, detail III). This load redistribution was possible because the roof structural solution works as a structural system [10].

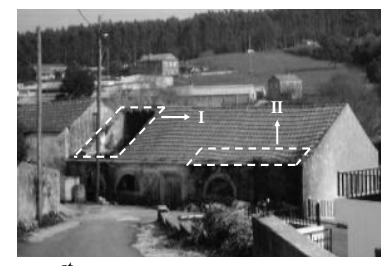

a. $1^{\text {st }}$ Collapse (2000)

Fig. 6.1. Roof's partial collapses

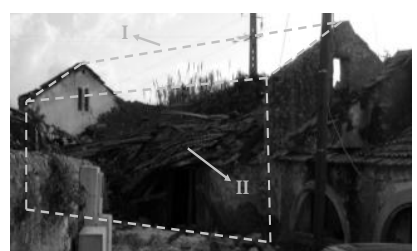

b. $2^{\text {nd }}$ Collapse (2007)

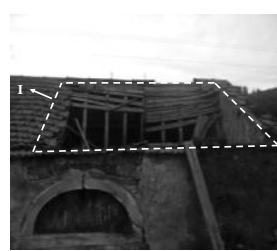

c. $3^{\text {rd }}$ Collapse (2009) 


\subsection{Pathologies}

This section is focused on the pathologies associated to the above described failures. Figure 6.1-a in its detail II shows a local permanent deformation of the roof system of the grindstone room in its connection to the frontal wall. Some ceramic tiles were also missing there.

Meanwhile, Figure 6.1-a illustrates the roof's condition of the grindstone room before the above described third roof's structural collapse occurred in 2009 (Fig. 6.1-c). Some purling and timbers boards showed an advanced stage of deterioration in the contact zone with the structural wall. Through Figure 5.1-a, detail I, it is also possible to notice that these timber elements had a darker shade than the similar ones located outside of the damaged zone which indicated a leaking problem. By doing a similar analysis, Figure 5.1-a, details VII, VIII and IX indicate that there were some cracked ceramic tiles or the ceramic tiles/timber board direct contact solution was not the appropriated one because may increase an undesirable water moister in the timber structural elements.

An expressive vertical crack located in the junction of the two limestone based masonry wall of the storage room (Fig. 6.2, detail I) was formed just before the occurrence of the second roof's structural collapse occurred in 2007.

\section{Reinforcement solutions}

In order to avoid the risk of leaking, a covering roof system is proposed in Fig. 7.1 .

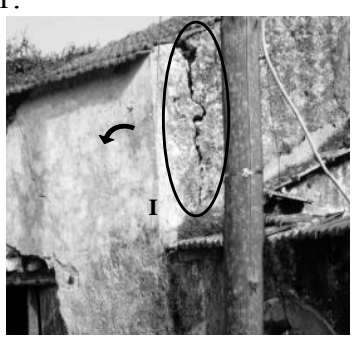

Fig. 6.2. Vertical crack, 2007

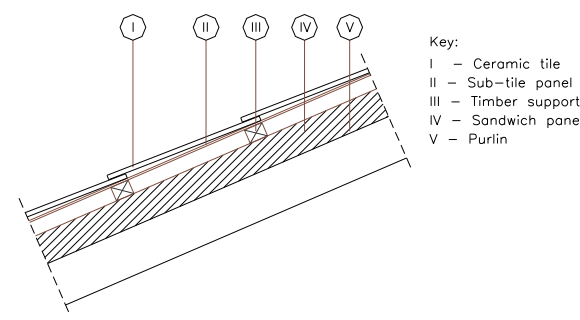

Fig. 7.1. Covering roof system`s detail

The option of using a sub-tile panel (Fig. 7.1, detail II) intended to avoid roof leaking in case of a ceramic tile cracks and to allow fixing this problem after a maintenance process. At the same time, the timber supporting solution (Fig. 7.1, detail III) avoids the direct contact between tile/main roof timber structure and, consequently, also it avoids the increasing of water moisture of timber structural elements which may result in either retraction effect or material deterioration.

In order to mitigate the structural failure seen in Figure 6.2, a structural reinforcement solution is proposed in Fig 7.2 which includes a steel tie (Fig. 7.2, detail III) and an earth based reinforcement beam (Fig. 7.2, detail II) as additional struc- 
tural elements. It is also considered that the timber beams should have a horizontal contact surface with the wall. The structural reinforcement of the junction of the masonry walls may be done according to Figure 7.3 in where the lengths $a$ and $b$ need to be specifically calculated.

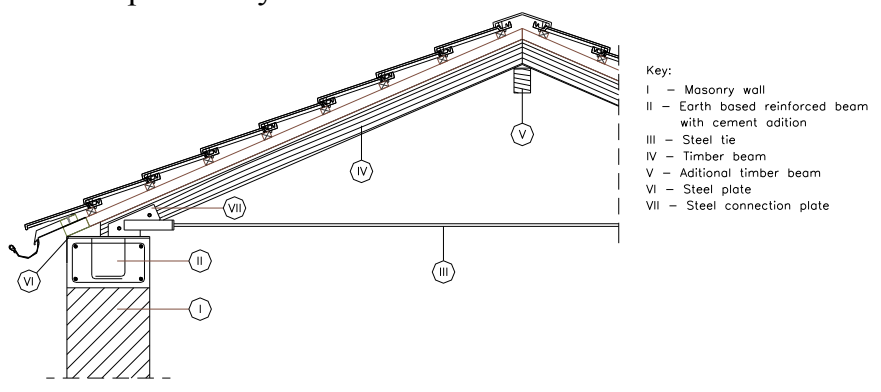

Fig. 7.2. Structural reinforcement solution of the roof of the storage room

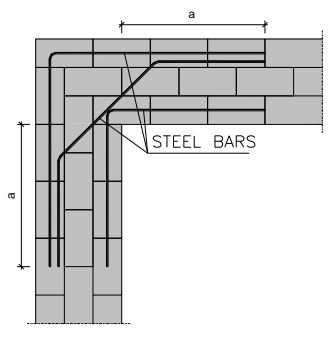

a. Junction steel reinforcement

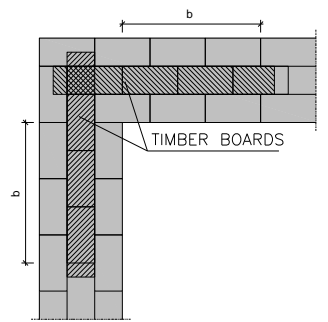

b. Junction timber reinforcement

Fig. 7.3. Structural reinforcement of the junction of the walls

On the base of achieving a sustainable construction solution, the steel element proposed above should be a reused one.

\section{Main conclusions}

A sustainable system flowchart is proposed in which the impact of the building industry is indicated.

The architecture solution, the structure solution, the building material's identification/characterization, the sequence of structural failures and the main pathologies identification/ characterization related to an early XX century Portuguese watermill were described and detailed.

The structural limestone based masonry walls adopted solution has the particularity of using small size limestone pieces connected by an earth based structural mortar which is also a sustainable and economic solution. 
The reported structural failure sequence has been caused basically by roof leaking problems which have been deteriorating the timber structural elements of the roof of the watermill building. The trussed timber roof structural solution had shown a better structural behavior than the beamed timber roof structural solution because it avoids total collapse and, consequently, it is more robust.

Some reinforcement solution details were proposed based on the failures and pathologies identified in the building. These repairing solutions proposals are also sustainable based since it was suggested to apply reused materials such as steel bars. These facts may be easily extrapolated to the repairing of the Portuguese traditional buildings which are in general environmental friendly.

\section{References}

[1] Carvalho J., Pinto T., Varum H., Jesus A., Lousada J., Morais J.; 2008; Construções em tabique na região de Trás-os-Montes e Alto Douro. CINPAR 2008. Portugal. 25-28 June 2008. Editors: Humberto Varum, Francisco Carvalho, Aníbal Costa, Alexandre Bertini, Petr Stepánek. ISBN: 978-989-95695-3-9.

[2] Pinto J., Blockley D., Woodman N. ;2002; The risk of vulnerable failure. Journal of Structural Safety, 24:107-122.

[3] Faria I., Freitas P., Pinto T., Jesus A., Valente A., Santos R., Silva P., Morais J.;2008; Monitorização da estrutura de madeira da cobertura da piscina municipal de Mirandela. CINPAR 2008 Portugal. 25-28 June 2008. Editors: H. Varum, F. Carvalho, A. Costa, A. Bertini, P. Stepánek. ISBN: 978-989-95695-3-9.

[4] KangHee L., YoungOh C., Chang-U C., DaeHee K.; 2007; "The estimation of the functional unit on energy consumption and $\mathrm{CO} 2$ emission concerned with construction of building". SB07 Seoul Conference; South Korea.

[5] www.cmlca.eu

[6] Baird G., Alcorn A., Haslam P.; 1997; "The energy embodied in building materials". IPENZ Transactions, New Zealand

[7] Pinto, J.; Varum, H.; Cruz, D.; Sousa, D.; Morais, P.; Tavares, P.; Lousada, J.; Silva, P.; Vieira, J. ;2009; Tabique Construction Characterization in Douro North Valley, Portugal: A First Step to Preserve this Architectural Heritage - $2^{\text {nd }}$ WSEAS International Conference on Urban Rehabilitation and Sustainability (URES'09) - Editors: Manoj Jha, Charles Long, Nikos Mastorakis, Cornelia Aida Bulucea, ISBN 978-960-474-136-6, ISSN 1790-5095, pp. 48-53 - Baltimore, USA, 7-9 November 2009.

[8] Silva, B.; Correia, J.; Nunes, F.; Tavares, P.; Varum, H.; Pinto, J. ;2009 ; - Earth Construction: Bird Teaching $-2^{\text {nd }}$ WSEAS International Conference on Urban Rehabilitation and Sustainability (URES'09), Editors: Manoj Jha, Charles Long, Nikos Mastorakis, Cornelia Aida Bulucea, ISBN 978-960-474-136-6, ISSN 1790-5095, pp. 72-78 - Baltimore, USA, 7-9 November 2009

[9] Murta A., Teixeira C., Varum H., Bentes I., Pinto J.;2009; Estudo do ganho energético associado à construção de uma habitação unifamiliar com recurso a materiais naturais no contexto português. VIII Seminario Iberoamericano de Construcción com Tierra (VIII SIACOT). Ed.: CRIATIAC - FAU - UNT. Tucumán, Argentina. ISBN EN TRÀMITE. pp. 151-161.

[10] CEN; 1998; Eurocode 5: Design of timber structures - Part 1-1: General - Common rules and rules for buildings. 